\title{
Pozzolanic Reaction Mechanism of Rice Husk Ash in Concrete - A Review
}

\author{
Siti Asmahani Saad ${ }^{1, a}$, Muhd Fadhil Nuruddin ${ }^{1, b}$, Nasir Shafiq ${ }^{1, c}$ \\ and Maisarah $\mathrm{Ali}^{2, \mathrm{~d}}$ \\ ${ }^{1}$ Universiti Teknologi PETRONAS, Bandar Seri Iskandar, 31750, Tronoh, Perak, Malaysia \\ ${ }^{2}$ International Islamic University Malaysia, P.O. Box 10, 50728, Kuala Lumpur, Malaysia \\ aasmahani.saad@gmail.com, ${ }^{\text {b}}$ fadhilnuruddin@petronas.com.my, ${ }^{c}$ nasirshafiq@petronas.com.my \\ and ${ }^{d}$ maisarah@iium.edu.my
}

Keywords: Rice husk ash; concrete; properties of rice husk ash; pozzolanic reaction determination.

\begin{abstract}
Recently, incorporation of cement replacement material (CRM) in concrete has gained considerable attention throughout the world. It is known that the commonly used CRM in current concrete industry is silica fume (SF), pulverized fuel ash (PFA) and rice husk ash (RHA). RHA is an agricultural waste from rice milling process. Rice farming activities is one of the main crops planted in Malaysia and therefore, the rice husk abundantly generated every year. RHA exhibits positive pozzolanic reaction during concrete strength development. The material contains amorphous silica and hence it contributed towards enhancement of various concrete properties. This paper presents a short review of RHA properties as CRM and pozzolanic reaction determination.
\end{abstract}

\section{Introduction}

Reducing global carbon footprint encourages explorations of the application of cement replacement materials (CRMs) in current concrete industry. CRM are commonly used in concrete as admixtures to enhance its properties and also to positively contribute from environmental point of view. In light of incorporating CRM into concrete production, rice husk ash (RHA) is regarded as one of them due to high silica content. Production of RHA is done via thermal activation, which is burning process of the rice husk from agricultural waste.

Rice plant is a type of plant that has the ability to take the silica content from soil. The absorbed silica is then eventually assimilates into its structure during the growth [1]. Therefore, the outer part which refers as rice husk possesses high silica content with value of more than $80 \%$ [2]. Approximately 1000 Million tons of rice is annually produced in the world, which usually leaves about 400 Million tons of rice husks as a waste material [3]. Hence, production of this beneficial ash as CRM from the abundant husk is possible. Therefore, utilizing RHA in concrete is possible. In addition, RHA posseses high content of amorphous silica and high specific surface area (SSA) that are possible to be achieved by adopting suitable burning condition [4].

\section{Properties of Rice Husk Ash}

Chemical Composition of Rice Husk Ash. There is an extensive study has been carried out to determine properties of rice husk ash. Table 1 summarizes the findings of RHA chemical proportion reported by various researchers. From the chemical composition analysis of RHA reported in Table 1 , it can be seen that RHA has high content of silica. This composition is responsible to pozzolanic reaction. Thus, it eventually contributes towards strength development in concrete. 
Table 1. Chemical properties of rice husk ash.

\begin{tabular}{|c|c|c|c|c|c|c|c|c|}
\hline \multicolumn{8}{|c|}{ Chemical Composition } & \multirow[t]{2}{*}{ Remarks } \\
\hline $\mathrm{SiO}_{2}$ & $\mathrm{Al}_{2} \mathrm{O}_{3}$ & $\mathrm{Fe}_{2} \mathrm{O}_{3}$ & $\mathrm{CaO}$ & MgO & $\mathrm{SO}_{3}$ & $\mathrm{~K}_{2} \mathrm{O}$ & LOI & \\
\hline 87.2 & 0.15 & 0.16 & 0.55 & 0.35 & 0.24 & 3.68 & 8.55 & Mehta [5] \\
\hline 87.3 & 0.15 & 0.16 & 0.55 & 0.35 & 0.24 & 3.68 & 8.55 & $\begin{array}{c}\text { Zhang et al. } \\
{[6]}\end{array}$ \\
\hline 86.9 & 0.84 & 0.73 & 1.40 & 0.57 & 0.11 & - & 5.14 & Bui et al. [7] \\
\hline 88.9 & 0.16 & 0.45 & 0.63 & 0.72 & 0.32 & 3.65 & - & $\begin{array}{c}\text { Nuruddin et } \\
\text { al. [8]; Chin } \\
\text { [9] }\end{array}$ \\
\hline 86.5 & 0.01 & 0.91 & 0.50 & 0.13 & - & 2.7 & 8.45 & $\begin{array}{l}\text { Zain et al. } \\
{[10]}\end{array}$ \\
\hline
\end{tabular}

\section{Mechanism of Reaction}

Pozzolanic Reaction Mechanism. As for conventional cement, (C-S-H) compound and portlandite $\left(\mathrm{Ca}(\mathrm{OH})_{2}\right)$ are the products of its hydration process. It produces together with four main compounds namely tricalcium silicate $\left(\mathrm{C}_{3} \mathrm{~S}\right)$, dicalcium silicate $\left(\mathrm{C}_{2} \mathrm{~S}\right)$, tricalcium aluminate $\left(\mathrm{C}_{3} \mathrm{~A}\right)$ and Tetracalcium aluminoferrite $\left(\mathrm{C}_{4} \mathrm{AF}\right)$. For all compounds, $\mathrm{C}, \mathrm{S}, \mathrm{A}$ and $\mathrm{F}$ are abbreviation of $\mathrm{CaO}$, $\mathrm{SiO}_{2}, \mathrm{AlO}_{3}$ and $\mathrm{Fe}_{2} \mathrm{O}_{3}$ respectively [11-12]. In this case, portlandite is left and no further reaction occurs to form additional C-S-H compounds. Excess calcium hydroxide can cause harm to concrete strength. It is simply because it tends to have the crystalline growth in one direction [13].

Pozzolan is a type of material that proven to improve concrete properties such as concrete strength, durability and impermeability [14]. Pozzolanic reaction will take place when reactive silica, which denoted as $\mathrm{SiO}_{2}$, is in amorphous state. Pozzolanic reaction mechanism is basically an acid-base reaction between silicium acid $\left(\mathrm{H}_{4} \mathrm{SiO}_{4}\right)$, which comes from the reactive amorphous silica and calcium hydroxide $\left(\mathrm{Ca}(\mathrm{OH})_{2}\right)$ [15]. It is also noted that pozzolanic reaction occurs whenever siliceous or aluminous material touch calcium hydroxide in adequate humidity level to form calcium silicate hydrate compound (C-S-H), which exhibit cementitious properties and contributes towards concrete strength development [16]. Fig. 1(a) illustrates the conventional cement hydration process without addition of pozzolan material. It is clearly seen that portlandite is left in the transition zone between aggregate and C-S-H paste. This weakest point leads to problems of concrete i.e. cracking of concrete. On the other hand, Fig. 1(b) shows the effect of pozzolanic material introduction in the hydration process. Portlandite is futher reacts with pozzolans and hence, producing extra C-S-H paste into the system. The followings are reactions occur in pozzolanic reaction mechanism [17].

$$
\begin{array}{lll}
\text { Pozzolan }+\mathrm{H}_{2} \mathrm{O} & \longrightarrow & \mathrm{H}_{2} \mathrm{SiO}_{4}{ }^{2-} \\
\mathrm{Ca}(\mathrm{OH})_{2}+\mathrm{H}_{2} \mathrm{O} & \longrightarrow & \mathrm{Ca}^{2+}+\mathrm{OH}^{-} \\
\mathrm{H}_{2} \mathrm{SiO}_{4}{ }^{2-}+\mathrm{Ca}^{2+} & \longrightarrow & \text { C-S-H (additional C-S-H) }
\end{array}
$$

Methods of Pozzolanic Reaction Determination. In measuring the pozzolanic reaction, several methodologies are adopted by various researchers namely rapid evaluation of pozzolanic activity by conductivity measurement, accelerated pozzolanic strength reactivity index (API), strength activity index (SAI) and Frattini test method [18-21].

Rapid evaluation of pozzolanic activity method is reported in 1989 by Luxan et al. It is a measurement of conductivity level, by using direct current measurement when a material is added into calcium hydroxide $\left(\mathrm{Ca}(\mathrm{OH})_{2}\right)$ saturated solution over time [18]. This test has been used widely 
by several researches for pozzolanic evaluation of sugar cane waste [22, 23], rice husk ash [24] and ferroalloy industry residue [25].

Accelerated pozzolanic strength reactivity index (API) is a determination of pozzolanic activity using modified ASTM C1240-05 "Standard Specification of Silica Fume Used in Cementitious Mixture". The API is given in terms of the equation as follows:

$$
\mathrm{API}=\mathrm{A} / \mathrm{B} \times 100 \%
$$

is the mean compressive strength of mortar containing pozzolan and $\mathrm{B}$ is the mean compressive strength of the reference mortar. Klimesch and Ray (1997) have adopted this method to test reactivity of metakaolin [26]. Meanwhile, Agarwal (2004) has also adopted this method in determining the pozzolanic level for rice husk ash, metakaolin and pulverized fuel ash [27].
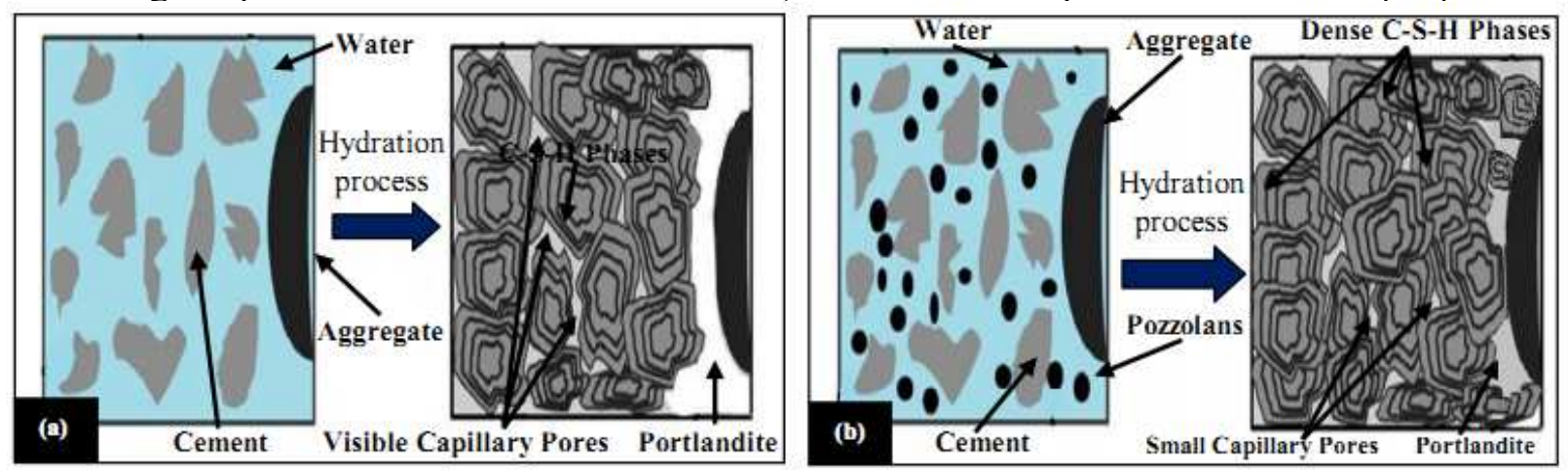

Fig. 1. Hydration process for (a) Conventional cement (b) Cement with addition of pozzolan as mineral additive through pozzolanic reaction [17].

Strength activity index (SAI) is an indirect measurement of physical properties of sample that indicates the extent of its pozzolanic activity. The test is in accordance with BS 3892 "Specification for Pulverized Fuel Ash for Use with Portland Cement". It encompasses of several properties tested i.e. compressive strength test. In this method, averages of three tests are reported in terms of percentage strength relative to the control mortar. The percentage is expressed as follows:

$$
\mathrm{SAI}=\mathrm{A} / \mathrm{B} \times 100 \%
$$

$\mathrm{A}$ is known as unconfined compressive strength of the pozzolan sample tested (MPa) while B is the unconfined compressive strength of the control mortar (MPa). SAI values of $80 \%$ and above at 28 days indicates the material tested exhibit pozzolanic activity [20].

Frattini test procedure involves chemical titration for determination of dissolved $\mathrm{Ca}^{2+}$ and $\mathrm{OH}^{-}$ concentration in a solution that contain CEM-I (ordinary portland cement) and the tested various type of pozzolan, namely metakaolin, and pulverized fuel ash. It is in accordance with BS EN196-5, "Method of Testing Cement. Part 5: Pozzolanicity Test for Pozzolanic Cement". According to Donatello et al. [28], there is a significant correlation between SAI method and Frattini test method, where $\mathrm{R}^{2}$ is found as 0.86 . Therefore, results from Frattini test and SAI method correlate with each other and are closely controlled methods.

Pozzolanic Reaction of Rice Husk Ash. It is proven that the introduction of pozzolan decreases the portlandite $\left(\mathrm{Ca}(\mathrm{OH})_{2}\right)$ content by the pozzolanic reaction to form additional C-S-H gel that can improve the concrete strength and durability [29].

Generally, amorphous silica that is ubiquitous in pozzolanic material reacts with lime vigorously compared to the material in crystalline state [30, 31]. According to Van et al. [32], it is found that RHA has small mean particle size, ranges between $95 \mu \mathrm{m}$ to $8.8 \mu \mathrm{m}$ with different grinding time and hence, it possesses high value specific surface area. Mesoporous structure of RHA allows the material to absorb water on internal and external surfaces. This condition permits $\mathrm{Ca}^{2+}$ ions to 
diffuse into its internal section and therefore hydration of cement and pozzolanic is continues for a long time.

\section{Conclusion}

The role and reaction of pozzolan materials in concrete have been discussed extensively. High content of reactive amorphous silica is vital in order to enhance the development of additional C-S$\mathrm{H}$ gel through pozzolanic activity. Potential usage of agricultural waste such as rice husk ash as CRM in concrete should be given considerable attention as this material contributes adverse impact to the environment. In addition, usage of this material is inline with sustainable construction development throughout the world.

\section{References}

[1] R.G. Smith and G.A. Kamwanja, The use of rice husk for making a cementitious material, Proc. Joint Symposium on the Use of Vegetable Plants and their Fibers as Building Material, Baghdad, 1986.

[2] F. Siddique, Waste materials and by-products in concrete: with 174 tables. Springer Press, 2008.

[3] International Rice Research Institute. Rough Rice Production by Country and Geographical Region 1961-2004. Rome: FAOSTAT Database, 2005.

[4] P.K. Mehta, Rice husk ash - a unique supplementary cementing material. In:Advances in concrete technology. 2nd edition. CANMET,. pp. 419-44, 1994.

[5] P.K. Mehta, Rice Husk Ash - A unique supplementary cementing material, Proceeding International Symposium on Advances in Concrete Technology, Editor. V.M. Malhotra,Athens, Greece, pp.407- 430, 1992.

[6] M.H. Zhang, R. Lastra, and V.M. Malhotra, Rice husk ash paste and concrete: Some aspects of hydration and the microstructure of the interfacial zone between the aggregate and paste. Cement and Concrete Research. Vol.26(6), pp. 963-977, 1996.

[7] D.D. Bui, J. Hu, and P. Stroeven, Particle size effect on the strength of rice husk ash blended gap-graded Portland cement concrete. Cement and Concrete Composites. Vol.27(3), pp. 357366, 2005.

[8] M.F. Nuruddin, A. Kusbiantoro and N. Shafiq, Microwave incinerated rice husk ash (MIRHA) and its effect on concrete properties, IMS International Conference, American University of Sharjah, 2008.

[9] S.C. Chin, Performance of used engine oil in fresh \& hardened states of normal and blended cement concretes, MSc Thesis, Universiti Teknologi PETRONAS, 2007.

[10] M. F. M. Zain, M. N. Islam, F. Mahmud, and M. Jamil, "Production of rice husk ash for use in concrete as a supplementary cementitious material," Construction and Building Materials, vol. 25, pp. 798-805, 2011.

[11] O.E. Omotosoa, D.G. Ivey and R. Mikulab, Characterization of chromium doped tricalcium silicate using SEM/EDS, XRD and FTIR, Journal of Hazardous Materials, Vol.42(1), pp.87$102,1995$.

[12] A. M. Neville, Properties of Concrete: Pearson Education, 2012.

[13] A.N. Givi, S.A. Rashid, F.N.A. Aziz, M.A.M. Salleh, Contribution of rice husk ash to the properties of mortar and concrete : a review, Journal of American Science, Vol 6(3), 2010.

[14] F.M. Lea, The Chemistry of Cement and Concrete, $3^{\text {rd }}$ ed., Edward Arnold, London, 1974

[15] D.J. Cook, Natural pozzolans. In: R.N. Swamy, Editor Cement Replacement Materials, Surrey University Press, pp. 200, 1986. 
[16] V.G. Papadakis, and S. Tsimas, Supplementary cementing materials in concrete: Part I: efficiency and design, Cement and Concrete Research, Vol. 32 (10), pp. 1525-1532, 2002.

[17] L.P. Singh, S.R. Karade, S.K. Bhattacharyya, M.M. Yousuf, and S. Ahalawat, Beneficial role of nanosilica in cement based materials - a review, Construction and Building Materials, Vol. 47, pp. 1069-1077, 2013.

[18] M.P. Luxan, F. Madruga, J. Saavedra, Rapid evaluation of pozzolanic activity of naturalproducts by conductivity measurement, Cement and Concrete Research, Vol. 19, pp.63-68, 1989.

[19] ASTM C1240-05: standard specification for silica fume used in cementitious mixtures. Philadelphia (USA): American Society for Testing and Materials; 2005.

[20] British Standard (BS) 3892. Pulverised-fuel ash. Part 1: specification for pulverised fuel ash for use with Portland cement; 1997.

[21] British Standard Euronorm (BS EN) 196. Methods of testing cement. Part 5: pozzolanicity test for pozzolanic cement; 2005.

[22] M. Frias, E. Villar-Cocina, M.I. Sanchez de Rojas and E. Valencia-Morales, "The effect that different pozzolanic activity methods has on the kinetic constants of the pozzolanic reaction in sugar cane straw-ash/lime systems: application of a kinetic-diffusive model". Cement Concrete Research, Vol.35 pp.2137-2142, 2005.

[23] M. Frias, E. Villar-Cocina and E. Valencia-Morales "Characterisation of sugar cane straw waste as pozzolanic material for construction: calcining temperature and kinetic parameters". Waste Manage, Vol.27, pp 533-538, 2007.

[24] S. Wansom, S. Janjathuraphan, and S. Sinthupinyo, "Pozzolanic Activity of Rice Husk Ash Comparison of various electrical methods," Journal of Metals, Materials and Minerals, vol. 19, pp. 1-7, 2009.

[25] M. Frias and C. Rodriguez, "Effect of incorporating ferroalloy industry wastes as complementary cementing materials on the properties of blended cement matrices," Cement Concrete Research, Vol.30, pp. 212-219, 2007.

[26] D.S. Klimesch and A. Ray, "Use of the second-derivative differential thermal curve in the evaluation of cement-quartz pastes with metakaolin addition autoclaved at $180{ }^{\circ} \mathrm{C}$ ". Thermochim Acta, Vol 307(2), pp.167-76, 1997.

[27] S. K. Agarwal, "Pozzolanic activity of various siliceous materials," Cement and Concrete Research, vol. 36, pp. 1735-1739, 2006.

[28] S. Donatello, M. Tyrer, and C. R. Cheeseman, "Comparison of test methods to assess pozzolanic activity," Cement and Concrete Composites, vol. 32, pp. 121-127, 2010.

[29] M.A.E. Aziz, S.A.E. Aleem, M. Heikal and H.E. Didamony, Hydration and durability of sulphate-resisting and slag cement blends in Caron's Lake water. Cement and Concrete Research. Vol.35(8), pp. 1592- 1600, 2005.

[30] R.B. Lin, S.M. Shih and C.F. Liu, Characteristics and relativities of $\mathrm{Ca}(\mathrm{OH})_{2} /$ silica fume sorbents for low temperature flue gas desulfurization, Chemical Engineering Science, Vol. 58 (16), pp. 3659-3668, 2003.

[31] G.A. Habeeb, and M.M. Fayyadh, Rice husk ash concrete: the effect of rha average particle size on mechanical properties and drying shrinkage, Australian Journal of Basic and Applied Sciences, Vol.3(3), pp. 1616-1622, 2009.

[32] V.-T.-A. Van, C. Rößler, D.-D. Bui, and H.-M. Ludwig, "Mesoporous structure and pozzolanic reactivity of rice husk ash in cementitious system," Construction and Building Materials, vol. 43, pp. 208-216, 2013. 